\title{
What Matters Most for Treatment Decisions in Hepatitis C: Effectiveness, Costs, and Altruism
}

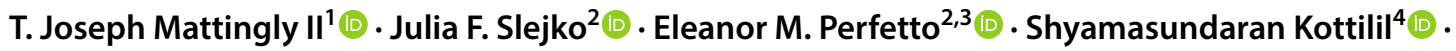 \\ C. Daniel Mullins ${ }^{2} \mathbb{B}$
}

Published online: 26 July 2019

(c) Springer Nature Switzerland AG 2019

\begin{abstract}
Objective Comparative evaluations of innovations in hepatitis C virus (HCV) drug therapy typically focus on sustained virologic response (SVR) without addressing psychological and socioeconomic challenges that extend beyond virologic cure. This study aims to identify and prioritize variables important to patients when making the decision to start HCV treatment. Methods A three-round Delphi process was conducted with the first round derived from a systematic literature review and advisory board input, including patients who have been affected by HCV, physicians, pharmacists, and a patient group representative. Delphi panelists were HCV patients who had received treatment or were considering treatment. Panelists were asked about factors influencing their HCV treatment decisions. Thematic analysis of open-ended responses based on grounded theory was used. Agreement with each category and rankings based on order of importance from the patient perspective was reported. Results Treatment effectiveness (100\% agreement), longer life (88\%), fear of complications (84\%), financial issues ( $80 \%$ ), quality of life (100\%), and impact on society $(80 \%)$ were considered important factors to patients in decisions to seek treatment. A fear of harming others (87\%) was considered more important than physical symptoms (83\%) in terms of patientreported problems caused by HCV. Medication costs (91\%) were identified as the most important costs of having HCV, followed by doctor costs $(77 \%)$.

Conclusions In addition to treatment effectiveness, patient experiences with financial problems, quality of life, and altruistic desires impact HCV patients' decisions. The risk of infecting others may motivate patients to seek treatment as much as personally experienced physical symptoms.
\end{abstract}

\section{Introduction}

Chronic hepatitis C virus (HCV) may impact over 3 million patients in the United States and has been associated with substantial costs related to care for advanced disease

Electronic supplementary material The online version of this article (https://doi.org/10.1007/s40271-019-00378-7) contains supplementary material, which is available to authorized users.

T. Joseph Mattingly II

jmattingly@rx.umaryland.edu

1 Department of Pharmacy Practice and Science, University of Maryland School of Pharmacy, 20 North Pine Street, N415, Baltimore, MD 21201, USA

2 Department of Pharmaceutical Health Services Research, University of Maryland School of Pharmacy, Baltimore, MD, USA

3 National Health Council, Washington, DC, USA

4 Institute of Human Virology, University of Maryland School of Medicine, Baltimore, MD, USA
[1-4]. One of the major challenges with HCV involves the extensive list of comorbid conditions that further complicate patients' lives. In 2016, a meta-analysis of 102 studies found the most common extrahepatic manifestations included chronic renal disease, diabetes mellitus, cardiovascular disease, Sjögren's syndrome, and depression [5]. These non-liver comorbidities often play a significant role in the health-related quality of life of $\mathrm{HCV}$ patients in addition to compounding health system economic burdens [5, 6]. A 2016 systematic review of HCV economic models suggested that the majority of methodological approaches to assess the cost effectiveness of HCV treatments may underestimate the value due to the omission of indirect benefits including the prevention of transmission, increased productivity, and extrahepatic benefits [7]. Incorporating these indirect benefits beyond liver-related outcomes may strengthen a treatment's value proposition for patients, payers, and society as a whole.

The evolution of patient engagement in research has advanced exponentially with the development of the 


\section{Key Points}

Comparative effectiveness research for hepatitis $\mathrm{C}$ virus (HCV) therapies typically focus on whether or not a treatment eliminates the virus from the patient. This study demonstrates that in addition to treatment effectiveness, patient experiences with financial problems, quality of life, and altruistic desires impact HCV patients' decisions.

Additionally, this study found that the risk of infecting others may motivate patients to seek treatment as much as personally experienced physical symptoms.

Patient-Centered Outcomes Research Institute in 2010, which funds patient-centered comparative effectiveness research (CER) along with other awards for organizations to build relationships and engage patient stakeholders [8]. A previously published literature search described the paucity of patient engagement methods in $\mathrm{HCV}$ cost-effectiveness research [9]. When HCV patients are engaged, a variety of clinical, social, psychological, and economic outcomes may be identified $[9,10]$.

The German Institute for Quality and Efficiency in Health Care developed a choice-based conjoint analysis pilot to identify, weight, and prioritize various attributes applied to chronic HCV leading to the development of a value assessment informed by patient preferences $[11,12]$. A discrete choice experiment questionnaire of 326 chronic $\mathrm{HCV}$ patients identified that even with inclusion of adverse effects and treatment burden in the questionnaire, treatment efficacy with sustained virologic response (SVR) at 6 months was the most important attribute of the treatment decision [13]. The research team repeated a similar process in a second sample of 561 chronic HCV patients and demonstrated SVR remained the most important treatment attribute followed by side effects such as anemia and rash [14]. In the final economic assessment of HCV treatments, eight attributes were included and weighted based on patient preference: probability of SVR, frequency of injection, therapy duration, gastrointestinal symptoms, anemia, skin reactions, tiredness, and headaches [12]. Other social or psychological variables captured in other HCV studies were not included [9].

The value assessment of direct-acting antivirals (DAAs) conducted by the Institute for Clinical and Economic Review in 2015 demonstrated very little patient engagement in their methodology and focused on the clinical outcomes related to development of decompensated cirrhosis, hepatocellular carcinoma, liver transplantation, or death from liverrelated causes [15]. To date, the inclusion of the patient voice through patient engagement as part of methods in cost-effectiveness research in existing published studies has been limited. This study aims to identify and prioritize outcomes important to patients in the evaluation of treatment decisions for future CER for chronic HCV.

\section{Methods}

Our methodology was based on the 10-Step Framework for Continuous Patient Engagement [16]. Patients and other stakeholders were continuously engaged to guide a patientonly Delphi panel in identifying and prioritizing outcomes to be used in future CER and economic evaluations of treatments for chronic HCV.

\subsection{Stakeholder Advisory Board}

Patients were engaged throughout this study through the formation of an 11-member, patient-centered, stakeholder advisory board (SAB) including four patients who have been affected by $\mathrm{HCV}$, three infectious disease specialists, one general practitioner, two pharmacists, and a national patient organization representative [17]. To promote patientcentricity, the SAB operated as follows: (1) board meeting agendas were created with patient advisors beginning and ending each SAB meeting with a brief story or experience to focus on the patient voice; (2) all SAB members used first names only to reduce intimidation; and (3) all materials were produced in a transparent way and shared with all members [18]. The SAB was engaged by the research team via inperson meetings or conference calls to provide input on (1) development of the research question; (2) the best approach for data collection with a patient-only Delphi panel; and (3) open-ended questions used in round one of the Delphi.

\subsection{Delphi Process}

A modified Delphi process (Fig. 1) was adapted to solicit feedback from the SAB to inform the initial questionnaire for a three-round Delphi to identify and prioritize inputs for real-world data evaluation and value assessment [19, 20]. The panel comprised patients who are experts on their disease, given their lived experience with HCV. Panel members were eligible by currently having HCV or previous experience with HCV but were cured after undergoing treatment. Panelists were recruited through the University of Maryland Institute of Human Virology, the American Liver Foundation, PatientsLikeMe ${ }^{\circledR}$, and patient-led private online support groups. Panelists maintained full anonymity throughout the study so that comments could be made freely without attribution. The Delphi technique was developed by the RAND Corporation in the 1950s as a way to build consensus among a panel of experts through an iterative series of 


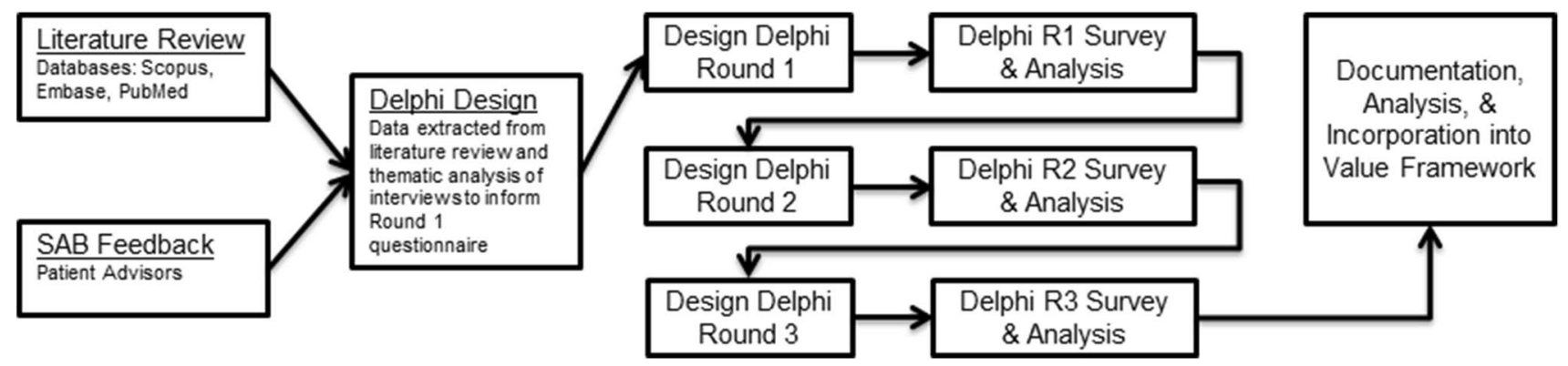

Fig. 1 Modified patient-only Delphi process with input from stakeholder advisory board (SAB) to identify and prioritize outcomes

questionnaires $[19,20]$. Since the Delphi group size does not depend on statistical power, group sizes vary widely in the published literature [21]. The target sample size for this panel was 20-30 patient experts to balance group dynamics and response rate with a large enough group to capture a wide range of opinions and judgments [20]. We anticipated a response rate of $65-85 \%$ for each round. A round was not considered complete for analysis until the $65 \%$ threshold for response rate was reached. As suggested by the SAB, response rates were improved by using email reminders and explaining the process and expectations thoroughly in advance.

The first Delphi round developed the initial base of knowledge, with questions informed by a literature review and input from the SAB [9]. The panel was asked for input regarding the factors or issues related to seeking (or not seeking) HCV treatment, problems caused by $\mathrm{HCV}$ in terms of health or well-being, and the costs they considered before getting treatment. Responses from round one were analyzed, summarized, and communicated back to the panel through a process of controlled feedback, which formulated the second round of questions; that is, initial survey results identified issues, questions, and terms to be addressed in the next round of surveys. Responses were analyzed and grouped using a grounded theory approach for each of the overarching dimensions: (1) factors related to seeking HCV treatment; (2) problems caused by HCV; and (3) costs considered before getting treatment [22]. The factors were presented along with exact text examples to the panelists in the second round for ratings on agreement or general comments. Panel agreement was determined for each factor with factors meeting the agreement threshold $(\geq 75 \%)$ carried forward. In the third round, panelists were asked to rank all factors that reached agreement from round two within each dimension in order of importance.

Survey distribution was completely online via Qualtrics ${ }^{\circledR}$ for all three Delphi rounds. Panelists were only communicated with through email throughout the Delphi process. Basic descriptive analytics were performed on all quantitative data. Level of agreement for quantitative rankings was assessed using Kendall's coefficient of concordance calculated in Microsoft Excel. This study was approved by the authors' institutional review board (Protocol number: HP-00080632). Members of the SAB were compensated for their time but Delphi panelists were not.

\section{Results}

A total of $30 \mathrm{HCV}$ patients agreed to participate, with all (30/30) panelists responding in round one, 83\% (25/30) in round two, and $70 \%(21 / 30)$ in round three. In terms of demographics, the panel comprised 17 (57\%) females and $23(77 \%)$ Whites, with a median age of 61.5 years (age range 30-78 years). Twenty-two panelists (73\%) were aware of how they contracted HCV. Patient-reported causes of HCV included intravenous drug use, blood transfusion, sexual intercourse, and receiving tattoos. Twenty-three panelists (77\%) were at SVR at the time the Delphi started and another four (13\%) were currently taking DAAs. Panelists responded with a wide variety of $\mathrm{HCV}$ treatment experiences with $77 \%$ (23/30) reporting experience with DAA therapy and only $13 \%$ (4/30) specifically reporting older regimens used before DAAs.

After round one, patients reported ten different categories of factors important in their decision to seek HCV treatment, seven different categories of problems caused by the disease, and eight different categories of cost considerations related to the disease or treatment (Table 1). Categories that reached our a priori level of agreement $(\geq 75 \%)$ based on round two responses were ranked within each domain in round three. Treatment effectiveness, longer life, fear of complications, financial issues, quality of life, and impact on society were considered important factors in determining patient decisions to seek treatment. A fear of harming others was considered more important than physical symptoms in terms of patient-reported problems caused by HCV. Medication costs were identified as the most important costs of having $\mathrm{HCV}$, followed by doctor costs (Table 2). 
Table 1 Agreement with factors related to treatment decision, problems caused by Hepatitis C virus (HCV), and costs identified with the disease or treatment

\begin{tabular}{|c|c|c|}
\hline Category & Examples of exact round 1 responses & $\begin{array}{l}\text { Agree- } \\
\text { ment } \\
(\%)^{\mathrm{a}} \\
N=25^{\mathrm{b}}\end{array}$ \\
\hline \multicolumn{3}{|l|}{ Factors important in seeking HCV treatment } \\
\hline Treatment effectiveness & $\begin{array}{l}\text { "Only having to take } 12 \text { weeks"; "High rate of cure"; "Less complications than } \\
\text { interferon" }\end{array}$ & 100 \\
\hline Fear of complications & "I didn't want to get worse"; "Prevent further liver damage"; "Fear of the unknown" & 84 \\
\hline Longer life & $\begin{array}{l}\text { "I wanted more time with my family"; "I wanted to live longer"; "I wanted to see my } \\
\text { grandchildren grow up" }\end{array}$ & 88 \\
\hline Physical symptoms & "Chronic fatigue"; "Hair loss"; "Leg Cramping"; "Flu-like symptoms" & 72 \\
\hline Psychological symptoms & "Mood”; "Anxiety”; "Depression"; "Emotional imbalance” & 68 \\
\hline Impact on society & "I didn't want to infect other people"; "I couldn't give blood" & 80 \\
\hline Quality of life & "Feeling better"; "Enjoying life more" & 100 \\
\hline Financial issues & "No insurance"; "Insurance denied"; "Paying out-of-pocket" & 80 \\
\hline Impact on other non-liver diseases & "I wanted treatment so I could be eligible for a kidney transplant" & 52 \\
\hline Impact on family or other relationships & "I want more time with my family"; "Having HCV has kept me from dating" & 68 \\
\hline \multicolumn{3}{|l|}{ Problems caused by HCV } \\
\hline Physical symptoms & $\begin{array}{l}\text { "Chronic fatigue"; "Hair loss"; "Leg cramping"; "Flu-like symptoms"; "cirrhosis"; } \\
\text { "liver cancer"; "achy joints"; "insomnia" }\end{array}$ & 83 \\
\hline Psychological symptoms & $\begin{array}{l}\text { "Mood"; "Anxiety"; "Depression"; "Emotional imbalance"; "Worry"; "Stress"; } \\
\text { "Inability to concentrate"; "Anger" }\end{array}$ & 74 \\
\hline Reduced quality of life & $\begin{array}{l}\text { "HCV has taken my quality of life from me"; "I couldn't do basic things like go } \\
\text { shopping" }\end{array}$ & 35 \\
\hline Social/relationship problems & $\begin{array}{l}\text { "HCV keeps me from having a relationship"; "Not able to go out for drinks"; "Not } \\
\text { being able to donate blood"; "Stigma or shame stuck with me" }\end{array}$ & 70 \\
\hline Burden on others & "My family had to watch me more"; "More demands on my family" & 43 \\
\hline Impact on other diseases & $\begin{array}{l}\text { "I was unable to take a medication for another problem because the medication might } \\
\text { hurt my liver" }\end{array}$ & 57 \\
\hline Fear of harming others & "I didn't want to infect other people"; "I couldn't give blood" & 87 \\
\hline \multicolumn{3}{|l|}{ Costs of disease or treatment } \\
\hline Direct costs-HCV medication costs & "Cost of drugs to treat HCV like Harvoni, Epclusa, etc." & 91 \\
\hline Direct costs—-side effects of HCV medication & "I had complications from interferon"; "Side effects from Harvoni" & 41 \\
\hline Direct costs-laboratory tests & "Blood work"; "Liver panels"; "Other labs" & 64 \\
\hline Direct costs-doctor costs & "Cost of going to a specialist"; "Office visits" & 77 \\
\hline Indirect costs-impact on work or career & "Too sick to keep working"; "Gave up significant income"; "Had to take leave" & 59 \\
\hline Indirect costs—impact on other diseases & $\begin{array}{l}\text { "I was unable to take a medication for another problem because the medication might } \\
\text { hurt my liver"; "Cost of waiting for a transplant" }\end{array}$ & 55 \\
\hline $\begin{array}{l}\text { Indirect costs—other fees in order to get } \\
\text { access to medication }\end{array}$ & $\begin{array}{l}\text { "Applying for a clinical trial"; "Applying for foundation grants"; "Costs of shipping } \\
\text { generics from India"; "Cost of interest on a loan for treatment" }\end{array}$ & 59 \\
\hline Indirect costs - time waiting for insurance & $\begin{array}{l}\text { "Had to jump through hoops to get insurance approval"; "Denied by insurance"; } \\
\text { "Waited until I turned } 65 \text { and could get Medicare" }\end{array}$ & 59 \\
\hline
\end{tabular}

aAgreement defined as $75 \%$ or more 'agree' or 'strongly agree'

${ }^{b} 25$ of 30 panelists responded in round 2

\section{Discussion}

Similar to previous studies examining patient preferences specific to chronic $\mathrm{HCV}$, our study identified treatment effectiveness as the top priority for patients considering undergoing therapy [12-14]. Additionally, the panel agreed mortality, morbidity, and direct costs typically reflected in current CER and economic evaluations of HCV were important to treatment decisions [7, 23]. Our study also supports previous work describing the perceived risks of future complications from $\mathrm{HCV}$ disease as an important determinant for patients considering whether to start treatment [24]. 
Table 2 Final ranked categories and level of agreement

\begin{tabular}{lll}
\hline Factors & $\begin{array}{l}\text { Agreement (\%) } \\
N=25\end{array}$ & $\begin{array}{l}\text { Mean ranking } \\
\text { (SD) } \\
N=21\end{array}$ \\
& & \\
\hline $\begin{array}{l}\text { Items important to seeking treat- } \\
\text { ment }\end{array}$ & 100 & $2.38(1.40)$ \\
Treatment effectiveness & 88 & $3.19(1.60)$ \\
Longer life & 84 & $3.24(1.64)$ \\
Fear of complications & 80 & $3.62(2.22)$ \\
Financial issues & 100 & $3.76(1.28)$ \\
Quality of life & 80 & $4.81(1.21)$ \\
Impact on society & & $1.48(0.51)$ \\
Problems caused by disease & 87 & $1.52(0.51)$ \\
Fear of harming others & 83 & $1.19(0.40)$ \\
Physical symptoms & & \\
Costs considered before treatment & & $1.81(0.40)$ \\
Direct costs—HCV medication & 91 & \\
$\quad$ costs & & \\
Direct costs—doctor costs & 77 &
\end{tabular}

${ }^{a}$ Rankings were calculated within each broad category

In terms of costs considered before entering treatment, our panel agreed that direct costs for medications and the costs related to visiting the doctor both impact treatment decisions and are frequently used in traditional cost-effectiveness analyses for HCV therapies [7, 9]. Costs of side effects, laboratory tests, and productivity losses identified by our panel are also frequently reported in economic evaluations in $\mathrm{HCV}$, but our panel did not reach consensus on these costs being important to treatment decisions. Given the lack of consensus with the Delphi panel, our advisory board felt that all costs may not apply to all patients and researchers may need to provide multiple analyses. The use of an impact inventory or checklist of costs, recommended by the Second Panel on Cost-Effectiveness in Health and Medicine, may provide a more transparent approach for multiple study perspectives and may be a step closer to more patient-centered economic evaluations [25]. Two additional cost categories identified by our panel that are not typically included in traditional cost-effectiveness studies are indirect costs related to gaining access to HCV medication and the time spent on insurance-related issues. While previous studies have identified administrative burdens related to accessing HCV medications as relevant, research is still needed to quantify these costs in order to consider them for economic evaluation [26-28].

A recurring theme our panel identified was the potential impact of patient altruism on treatment decisions. This has been identified in other diseases, but not previously discussed in the context of CER for HCV treatments [29-31]. Our panel agreed that their impact on society without direct personal benefit was an important factor in the decision to seek treatment, but the item ranked last in that category. However, the fear of potentially harming others was the most important problem identified by our panel when compared with their own physical symptoms (Table 2). The fear of harming others has been identified as an important problem for patients across many infectious diseases including HCV, hepatitis B virus, human immunodeficiency virus, methicillin-resistant Staphylococcus aureus, and severe acute respiratory syndrome [32-36]. Interviews from 36 individuals with hepatitis B virus or HCV in 2008 identified "infecting family members" and "infecting others" as the most frequently reported concern [32]. While reducing one's own fear of harming someone else does not represent pure altruism since the individual gains the psychological benefits of less fear, the act of ranking potentially harming others over one's own physical experience may overlap with the altruism construct. Despite the fact that patients have reported this concern, CER evaluating treatments that reduce further transmission of HCV may consider this a societal factor but not one that actually benefits the individual who may now experience peace of mind at no longer being infectious [37]. Recently, the International Society of Pharmacoeconomics and Outcomes Research Special Task Force on US Value Assessment Frameworks identified 'fear of contagion' as a value element to consider for infectious diseases as reducing or avoiding this anxiety associated with the risk of spreading disease may be of value to some patients [38]. The potential value of reducing this fear in people with $\mathrm{HCV}$ has not been identified in any published economic models evaluating $\mathrm{HCV}$ treatments.

This study has several potential limitations. Additional extrahepatic manifestations of $\mathrm{HCV}$ disease, psychological symptoms, and social/relationship issues were identified as important for several patients in our panel, but these items failed to meet the $75 \%$ a priori agreement level to be maintained in the final model. Deeper qualitative interviews of HCV patients who inject drugs have described how a cure removed the need to disclose the disease, allowing patients to rebuild their identity and potentially enhance future social connections [39]. Our approach of using a consensus definition may focus attention on items where the 'average patient' would agree, but failing to consider all items captured in the data may miss one very important factor for a small subset of patients [40]. For example, only 35\% of patients in our panel agreed that $\mathrm{HCV}$ causes additional burdens on other family members. Assuming this means that caregiver burden is not important in the evaluation of HCV treatment may undervalue the impact that a cure could have on patients who do rely heavily on others. Throughout the rounds, examples provided by panelists may overlap with multiple factors or categories. For example, 'more time with family' was included as example text shared in both the 'longer life' and 'impact on family' factors for patients in the second and third rounds. 
In this study, the Delphi approach allowed additional variables not traditionally considered in CER to be maintained throughout as patients were not limited in how many items they could keep. All items were identified directly from the specific text of responses of patients with real-world experience with the disease using grounded theory, rather than an a priori set of items pre-specified by the research team. Since we relied on the text provided by the panel, items related to older interferon-based therapies were included by our panelists but may not be as relevant to future evaluations of DAAs. The systematic review and SAB created the overarching categories to create an initial questionnaire focusing on factors related to seeking HCV treatment, problems causes by HCV, and costs considered before getting treatment. However, the open-ended response format provided an environment for the natural emergence of categories within each dimension driven by patient perspectives [41].

A key component to the Delphi technique involves the selection of experts [42]. Our experts were defined based on their lived experience with $\mathrm{HCV}$ disease rather than clinical or technical expertise. While we aimed for a panel representative of a broad HCV community, opinions of patients willing to participate in research may not fully capture or could be different from the opinions of those who refuse to participate. Given the stigma often associated with HCV disease, our panel may have underestimated the impact of psychological or social problems as people with HCV who continue to experience psychosocial issues with their diagnosis may have been less likely to accept our panel invitation. While we had a wide age range of panelists, the median age of the panel shows that more than half of the panel were in their 1960s. Additionally, we did not ask panelists to self-report their current status or history of drug use. Future researchers may consider purposefully sampling a younger population, active intravenous drug users, or those not linked to care.

The use of an SAB was to guide research decisions and incorporate patient, provider, and researcher input. However, only having four patient advisors included alongside physicians and researchers on the SAB may have limited participation if patients felt intimidated during meetings. While all advisors were compensated equally and we used first names rather than formal titles during any deliberation, this risk could not be completely eliminated.

In addition to developing a patient-guided list of variables and outcomes to be included in future CER or economic evaluations, this study demonstrates how patients and other stakeholders can be engaged throughout the research process. By continuously engaging the $\mathrm{SAB}$, patients were involved at all stages from topic solicitation and question framing to study design and dissemination. This type of approach could be utilized for many different research methodologies to promote the development of patient-centered evidence that is easily disseminated to those with the most at stake - the patients and their families.

\section{Conclusion}

Traditional elements included in HCV economic assessments do not include all elements valued by people with $\mathrm{HCV}$. Our results suggest that in addition to treatment effectiveness, patient experiences with financial problems, quality of life, and altruistic desires may impact patients' decisions. The risk of infecting other people may drive patients to seek treatment as much as patients hope that treatment will ameliorate the physical symptoms personally experienced, reflecting an altruistic component in outcomes desired by patients. The direct costs of medications and visits to the doctor were identified as the most important costs to consider when seeking treatment.

Acknowledgements The authors would like to thank the patient-centered advisory board members for their contribution to the concept, design, and interpretation of this study.

Author contributions Study concept and design: all; drafting of manuscript: TJM; critical reviews: all; statistical analysis: TJM; interpretation of data: all; final version approval: all.

Funding The Stakeholder Advisory Board described in this manuscript was initiated with a research grant from the Patient Centered Outcomes Research Institute.

Data Availability Statement All data generated or analyzed during this study are included in this published article (and its supplementary information files).

\section{Compliance with ethical standards}

Conflict of interest TJM reports consultant fees from G\&W Labs, $\mathrm{BMS}$, and NHC, all unrelated to this research; EMP is an employee of the National Health Council, which receives membership dues and sponsorship funding from a wide range of organizations. For the full list, please see www.nhcouncil.org; JFS reports grants from the PhRMA Foundation and PhRMA unrelated to this work; SK reports grants from Gilead Sciences, Merck, and Arbutus Pharma; CDM reports grants from Merck and consulting fees from Bayer, BoehringerIngelheim, Illumina, Janssen, Merck, Pfizer, Regeneron, and Sanofi.

\section{References}

1. Denniston MM, Jiles RB, Drobeniuc J, Klevens RM, Ward JW, McQuillan GM, et al. Chronic Hepatitis C Virus Infection in the United States, National Health and Nutrition Examination Survey 2003 to 2010. Ann Intern Med. 2014;160:293-300.

2. Menzin J, White LA, Nichols C, Deniz B. The economic burden of advanced liver disease among patients with hepatitis $\mathrm{C}$ virus: a large state Medicaid perspective. BMC Health Serv Res. 2012;12:459. 
3. Davis KL, Mitra D, Medjedovic J, Beam C, Rustgi V. Direct economic burden of chronic hepatitis $\mathrm{C}$ virus in a United States managed care population. J Clin Gastroenterol. 2011;45:e17-24.

4. El Khoury AC, Vietri J, Prajapati G. The burden of untreated hepatitis c virus infection: a US patients' perspective. Dig Dis Sci. 2012;57:2995-3003.

5. Younossi Z, Park H, Henry L, Adeyemi A, Stepanova M. Extrahepatic manifestations of hepatitis C: a meta-analysis of prevalence, quality of life, and economic burden. Gastroenterology. 2016;150:1599-608.

6. Leidner AJAJ, Chesson HWHW, Spradling PRPR, Holmberg SDSD. Assessing the effect of potential reductions in non-hepatic mortality on the estimated cost-effectiveness of hepatitis $C$ treatment in early stages of liver disease. Appl Health Econ Health Policy. Springer International Publishing; 2016;15:1-10.

7. Chhatwal J, He T, Lopez-Olivo MA. Systematic review of modelling approaches for the cost effectiveness of hepatitis $\mathrm{C}$ treatment with direct-acting antivirals. Pharmacoeconomics. Springer International Publishing. 2016;34:551-67.

8. Forsythe L, Heckert A, Margolis MK, Schrandt S, Frank L. Methods and impact of engagement in research, from theory to practice and back again: early findings from the patient-centered outcomes research institute. Qual Life Res. 2018;27:17-31.

9. Mattingly TJ II, Perfetto EM, Johnson SL. Engaging hepatitis C infected patients in cost-effectiveness analyses: a literature review. Hepatology. 2018;23:774-81.

10. Evon DM, Golin CE, Stoica T, Jones RE, Willis SJ, Galanko J, et al. What's important to the patient? Informational needs of patients making decisions about hepatitis $\mathrm{C}$ treatment. Patient. 2017; 10:335-44.

11. Institute for Quality and Efficiency in Health Care. Choice-based Conjoint Analysis -- Pilot Project to Identify, Weight, and Prioritize Multiple Attributes in the Indication "Hepatitis C" [Internet]. Cologne, Germany: Institute for Quality and Efficiency in Health Care (IQWiG); 2014 Jul 23. Available from http://www.ncbi.nlm. nih.gov/books/NBK385771/

12. Mühlbacher AC, Sadler A, Muhlbacher AC, Sadler A, Mühlbacher AC, Sadler A. the probabilistic efficiency frontier: a framework for cost-effectiveness analysis in germany put into practice for hepatitis c treatment options. Value Health. 2017;20:266-72.

13. Mühlbacher AC, Bridges JFP, Bethge S, Dintsios C-M, Schwalm A, Gerber-Grote A, et al. Preferences for antiviral therapy of chronic hepatitis C: a discrete choice experiment. Eur J Health Econ. 2017;18:155-65.

14. Mühlbacher A, Bethge S. First and foremost battle the virus: eliciting patient preferences in antiviral therapy for hepatitis $\mathrm{C}$ using a discrete choice experiment. Value Health. 2016;19:776-87.

15. Tice JA, Ollendorf DA, Chahal HS, Kahn JG, Marseille E, Weissberg $\mathrm{J}$, et al. The comparative clinical effectiveness and value of novel combination therapies for the treatment of patients with genotype 1 chronic hepatitis c infection: a technology assessment. Institute for Clinical and Economic Review. 2015 Jan 30. Available from https://icer-review.org/wp-content/uploads/2016/01/ CTAF_HCV2_Final_Report_013015.pdf

16. Mullins CD, Abdulhalim AM, Lavallee DC. Continuous patient engagement in comparative effectiveness research. JAMA. 2012;307:1587-8.

17. Patient-Centred Outcomes Research Institute. Engaging an underserved patient community to inform and improve comparative effectiveness research for hepatitis $\mathrm{C}$ treatments [Internet]. 2018. https://www.pcori.org/research-results/2017/engaging-underserve d-patient-community-inform-and-improve-comparative. Accessed 22 Oct 2018.

18. Perfetto EM, Oehrlein EM, Boutin M, Reid S, Gascho E. Value to whom? The patient voice in the value discussion. Value Health. 2017;20:286-91.
19. Helmer O. Analysis of the future: the Delphi method. California: Santa Monica; 1967.

20. Hsu C, Sandford B. The delphi technique: making sense of consensus. Pract. Assessment, Res Eval. 2007;12:1-8.

21. Powell C. The Delphi technique: myths and realities. Methodol J Adv Nurs. 2003;41:376-82.

22. Creswell JW, Poth CN. Qualitative inquiry and research design: Choosing among five approaches. Sage publications; 2017.

23. Chou R, Hartung D, Rahman B, Wasson N, Cottrell EB, Ru R. Comparative effectiveness of antiviral treatment for hepatitis $\mathrm{c}$ virus infection in adults: a systematic review. Ann Intern Med. 2013;158:114-23.

24. Fraenkel L, Chodkowski D, Lim J, Garcia-Tsao G. Patients preferences for treatment of hepatitis C. Med Decis Mak. 2010;30:45-57.

25. Sanders GD, Neumann PJ, Basu A, Brock DW, Feeny D, Krahn $\mathrm{M}$, et al. Recommendations for conduct, methodological practices, and reporting of cost-effectiveness analyses. JAMA. 2016;316:1093-103.

26. Do A, Mittal Y, Liapakis A, Cohen E, Chau H, Bertuccio C, et al. Drug authorization for sofosbuvir/ledipasvir (harvoni) for chronic HCV infection in a real-world cohort: a new barrier in the HCV care cascade. PLoS One. 2015;10:1-15.

27. Dunn EEE, Vranek K, Hynicka LMM, Gripshover J, Potosky D, Mattingly TJJ. Evaluating a Collaborative Approach to Improve Prior Authorization Efficiency in the Treatment of Hepatitis C Virus. Qual. Manag. Health Care [Internet]. 2017;26:136-9. https://www.scopus.com/inward/record.uri?eid=2-s2.0-85021 $814470 \&$ doi $=10.1097 \% 2 \mathrm{FQMH} .0000000000000137 \&$ partn erID $=40 \& m d 5=5 d 46 b 90$ ebb71fec39f3605f662591787.

28. Clements KM, Clark RE, Lavitas P, Kunte P, Graham CS, O'Connell E, et al. Access to new medications for hepatitis $\mathrm{C}$ for medicaid members: a retrospective cohort study. J Manag Care Spec Pharm. 2016;22:714-22.

29. Riggs KR, Ubel PA, Saloner B. Can appealing to patient altruism reduce overuse of health care services? An experimental survey. J Gen Intern Med. 2017;32:732-8.

30. Hershey JC, Asch DA, Thumasathit T, Meszaros J, Waters VV. The roles of altruism, free riding, and bandwagoning in vaccination decisions. Organ Behav Hum Decis Process. 1994;59:177-87.

31. Jasper JD, Nickerson CAE, Ubel PA, Asch DA. Altruism, incentives, and organ donation attitudes of the transplant community. Med Care. 2004;42:378-86.

32. Alizadeh AHM, Ranjbar M, Yadollahzadeh M. Patient concerns regarding chronic hepatitis $\mathrm{B}$ and $\mathrm{C}$ infection. East Mediter Health J. 2008;14:1142-7.

33. Keegan A, Lambert S, Petrak J. Sex and relationships for HIVpositive women since HAART: a qualitative Search details. AIDS Patient Care STDS. 2005;19:645-54.

34. Andersson H, Lindholm C, Fossum B. MRSA-global threat and personal disaster: patients' experiences. Int Nurs Rev. 2011;58:47-53.

35. Ho SMY, Kwong-Lo RSY, Mak CWY, Wong JS. Fear of severe acute respiratory syndrome (SARS) among health care workers. J Consult Clin Psychol. 2005;73:344-9.

36. Richmond JA, Ellard J, Wallace J, Thorpe R, Higgs P, Hellard $\mathrm{M}$, et al. Achieving a hepatitis $\mathrm{C}$ cure: a qualitative exploration of the experiences and meanings of achieving a hepatitis $\mathrm{C}$ cure using the direct acting antivirals in Australia. Hepatol Med Policy. 2018;3:1-9.

37. Harris M. Managing expense and expectation in a treatment revolution: problematizing prioritisation through an exploration of hepatitis C treatment 'benefit.' Int J Drug Policy. Elsevier B.V.; 2017;47:161-8.

38. Lakdawalla DN, Doshi JA, Garrison LP, Phelps CE, Basu A, Danzon PM. Defining elements of value in health care-a health 
economics approach: an ISPOR special task force report [3]. Value Heal. Elsevier Inc.; 2018;21:131-9.

39. Madden A, Hopwood M, Neale J, Treloar C. Beyond cure: patient reported outcomes of hepatitis $\mathrm{C}$ treatment among people who inject drugs in Australia. Harm Reduct J Harm Reduct J. 2018;15:1-8.

40. Graff JS, Grasela T, Meltzer DO, Dubois RW. Individual treatment effects: implications for research, clinical practice, and policy. Am J Manag Care. 2014;20:544-51.
41. Garson GD. Grounded theory. 2016th ed. Asheboro: Statistical Associates Publishers; 2016.

42. Okoli C, Pawlowski SD. The Delphi method as a research tool: an example, design considerations and applications. Inf Manag. 2004;42:15-29. 